\title{
Case-control study of the PERIOD3 clock gene length polymorphism and colorectal adenoma formation
}

\author{
MELANNIE ALEXANDER ${ }^{1,2}$, JAMES B. BURCH $^{1-3}$, SUSAN E. STECK $^{1,2}$, CHIN-FU CHEN $^{4}$, \\ THOMAS G. HURLEY ${ }^{1}$, PHILIP CAVICCHIA ${ }^{1,2,5}$, MEREDITH RAY ${ }^{2}$, NITIN SHIVAPPA $^{1,2}$, \\ JACLYN GUESS $^{1,2}$, HONGMEI ZHANG ${ }^{6}$, SHAWN D. YOUNGSTEDT ${ }^{7}$, KIM E. CREEK $^{8}$, \\ STEPHEN LLOYD ${ }^{9}$, XIAOMING YANG ${ }^{10}$ and JAMES R. HÉBERT ${ }^{1,2,11}$
}

\begin{abstract}
${ }^{1}$ South Carolina Statewide Cancer Prevention and Control Program, University of South Carolina, Columbia, SC;
${ }^{2}$ Department of Epidemiology and Biostatistics, Arnold School of Public Health, University of South Carolina, Columbia, SC;

${ }^{3}$ Dorn Department of Veterans Affairs Medical Center, Columbia, SC; ${ }^{4}$ Center for Molecular Studies,

Greenwood Genetic Center, Greenwood, SC; ${ }^{5}$ Bureau of Epidemiology, Division of Disease Control and Health Protection,

Florida Department of Health, Tallahassee, FL; ${ }^{6}$ Division of Epidemiology, Biostatistics and Environmental Health,

School of Public Health, University of Memphis, Memphis, TN; ${ }^{7}$ College of Nursing and Health Innovation, and

College of Health Solutions, Arizona State University, Phoenix, AZ; ${ }^{8}$ Department of Drug Discovery and Biomedical Sciences,

South Carolina College of Pharmacy, University of South Carolina; ${ }^{9}$ South Carolina Medical Endoscopy Center,

and Department of Family Medicine, University of South Carolina School of Medicine, Columbia, SC;

${ }^{10}$ Medical Chronobiology Laboratory, Dorn Department of Veterans Affairs Medical Center, Columbia, SC;

${ }^{11}$ Department of Family and Preventive Medicine, School of Medicine, University of South Carolina, Columbia, SC, USA
\end{abstract}

Received August 9, 2014; Accepted September 18, 2014

DOI: $10.3892 /$ or.2014.3667

\begin{abstract}
Clock genes are expressed in a self-perpetuating, circadian pattern in virtually every tissue including the human gastrointestinal tract. They coordinate cellular processes critical for tumor development, including cell proliferation, DNA damage response and apoptosis. Circadian rhythm disturbances have been associated with an increased risk for colon cancer and other cancers. This mechanism has not been elucidated, yet may involve dysregulation of the 'period' (PER) clock genes, which have tumor suppressor properties. A variable number tandem repeat (VNTR) in the PERIOD3 (PER3) gene has been associated with sleep disorders, differences in diurnal hormone secretion, and increased premenopausal breast cancer risk. Susceptibility related to $P E R 3$ has not been examined in conjunction with adenomatous polyps. This exploratory case-control study was the first to test the hypothesis that the 5-repeat PER3 VNTR sequence is associated with increased odds of adenoma formation. Information on demographics, medical history, occupation and lifestyle was collected prior to colonoscopy. Cases $(n=49)$ were individuals with at least one histopathologically confirmed adenoma. Controls $(n=97)$
\end{abstract}

Correspondence to: Dr James B. Burch, Department of Epidemiology and Biostatistics, University of South Carolina, 915 Greene Street Suite 200, Columbia, SC 29208, USA

E-mail: burch@mailbox.sc.edu

Key words: adenoma, clock gene, circadian rhythm, colorectal cancer, variable number tandem repeat included patients with normal findings or hyperplastic polyps not requiring enhanced surveillance. Unconditional multiple logistic regression was used to calculate odds ratios (ORs) with 95\% confidence intervals (CIs), after adjusting for potential confounding. Adenomas were detected in $34 \%$ of participants. Cases were more likely to possess the 5-repeat PER3 genotype relative to controls (4/5 OR, 2.1; 95\% CI, 0.9-4.8; 5/5 OR, 5.1; 95\% CI, 1.4-18.1; 4/5+5/5 OR, 2.5; 95\% CI, 1.7-5.4). Examination of the Oncomine microarray database indicated lower PERIOD gene expression in adenomas relative to adjacent normal tissue. Results suggest a need for follow-up in a larger sample.

\section{Introduction}

According to recent estimates, over 136,000 new patients and more than 50,000 deaths occurred in 2014 in the USA due to colorectal cancer (CRC), which makes it the third most common and deadly cancer among both men and women (1). Colorectal adenomatous polyps are the primary precursor lesions for CRC, accounting for $85-90 \%$ of cases (2). Developing a better understanding of factors related to adenoma susceptibility and progression thus represents an important goal for CRC prevention.

Disruption of circadian rhythms or clock gene expression is emerging as a novel and potentially modifiable cancer risk factor, although the pathophysiological mechanism is incompletely understood $(3,4)$. The central circadian pacemaker is located in the suprachiasmatic nuclei (SCN) of the anterior hypothalamus. Generation of circadian rhythms is accomplished primarily via photic input from the retina, which synchronizes the reciprocal transcriptional-translational 
expression of at least nine core clock genes: PER1, PER2, PER3, CRY1, CRY2, CLOCK, BMAL1, TIM and CK1E (3-5). In most tissues, this system facilitates the diurnal expression of $\sim 10 \%$ of the entire mammalian genome via genetic and epigenetic regulation of clock-controlled genes (6-10). Various factors, such as shift work, late bedtimes or poorly timed light exposure can disrupt endogenous circadian timing, thus altering clock gene expression and the cellular processes they help regulate (4). Since clock genes regulate processes that are considered hallmarks of carcinogenesis (cell cycle control, DNA damage response, apoptosis), their dysregulation may serve as an underlying biological mechanism linking altered circadian rhythms with cancer (4,11-15). Clock gene polymorphisms have been associated with non-Hodgkin's lymphoma and cancers of the breast and prostate (4). Clock gene polymorphic variation also influences sleep regulation $(5,16,17)$, which may contribute to increases in cancer susceptibility that have been observed among people who experience circadian rhythm disturbances or sleep disruption (18-21). For example, shift work and sleep disturbances have been associated with increased CRC risk (20,22-24) and truncated sleep ( $<6 \mathrm{~h} / \mathrm{night})$ has been associated with an increased odds of colorectal adenoma formation relative to adenoma-free controls (18).

The period (PER) clock genes have immunomodulatory $(5,25,26)$ and tumor suppressor properties $(4,11,19,27,28)$. Mutation or altered expression of $P E R$ genes has been observed among cancer patients relative to controls, within human tumors relative to adjacent normal tissue and in experimental cancer bioassays $(4,11,27,29-36)$. Whether differential expression of $P E R$ or other clock genes occurs in human adenomas versus normal tissue is not known. The PER3 variable number tandem repeat (VNTR; rs57875989) length polymorphism contains 4 or 5 copies of a 54-bp sequence encoding 18 amino acids. The 5 -repeat variant adds several potential phosphorylation motifs to the gene, and $P E R 3$ 's interaction with circadian processes may be enhanced among those individuals $(16,37)$. The 5-repeat PER3 allele is associated with a relatively penetrant phenotype that includes morning circadian preference $(16,38,39)$, increased cognitive decline in response to sleep deprivation (16), differences in levels or timing of melatonin or cortisol secretion $(37,40,41)$, and a tendency towards depressive symptoms or an earlier onset of bipolar disorder $(42,43)$. PER3 is considered a candidate tumor suppressor gene $(27,28,33)$, and the 5/5 PER3 VNTR genotype has been associated with increased premenopausal breast cancer risk (33), though not consistently $(21,44)$. Recently, the relationship between the PER3 VNTR and CRC risk was examined in Greece and no association was observed, although a relatively small portion of the study population was homozygous for the 5-repeat allele $(<2 \%)$, and differences in genotype frequency among cases and controls were not adjusted for potential confounding (45). The role of PER3 or other clock genes in human adenoma formation has yet to be examined in detail. Therefore, this exploratory study tested the hypothesis that adenoma cases are hetero- or homozygous for the 5-repeat PER3 variant relative to adenoma-free controls.

\section{Materials and methods}

Participants and data from two different endoscopy centers in the Columbia, SC metropolitan area were pooled for this anal- ysis; the South Carolina Medical Endoscopy Center (Site 1, $\mathrm{n}=93$ ), and the WJB Dorn Veterans Administration Medical Center (DVAMC; Site 2, n=53). Eligible patients were English literate adults 30-80 years who were scheduled for a screening or surveillance colonoscopy at either site. The present study was approved by the Institutional Review Boards (IRB) of the DVAMC and the University of South Carolina prior to informed consent and enrollment. Participants provided a peripheral blood sample for DNA recovery and completed a questionnaire to ascertain information on: demographic (gender, marital status, income, race, ethnicity), lifestyle (smoking history, diet, physical activity), and occupational (employment status, job industry, type of shift, history of shift work) factors, as well as personal and family history of cancer and other chronic diseases. Individuals who were getting a colonoscopy due to symptoms (presence of gastrointestinal bleeding, hematochezia, melena, fecal occult blood, iron deficiency or constipation) were collapsed into the screening category due to low counts $(n=10)$. Cases were defined as individuals with at least one histologically confirmed adenoma, and controls were subjects with a normal colonoscopy or a normal biopsy not requiring heightened surveillance (e.g., hyperplastic polyp).

Genomic DNA was extracted and genotyping for the PER3 VNTR sequence was performed using previously described methods $(42,46)$. For participants recruited from Site 1, the PER3 VNTR sequence was amplified via polymerase chain reaction (PCR) using the following forward (5'-TGGCAGTGA GAGCAGTCCT-3') and reverse (5'-AGTGGCAGTAGGATGG GATG-3') primers $(33,44)$. The final $20 \mu 1$ PCR reaction mixture was made up of $1 \mu \mathrm{l}(20 \mathrm{ng})$ of genomic DNA, $10 \mu \mathrm{l}$ of OneTaq $^{\circledR}$ Hot Start $2 \mathrm{X}$ Master Mix with standard buffer (20 mM Tris- $\mathrm{HCl}, 22 \mathrm{mM} \mathrm{KCl}, 22 \mathrm{mM} \mathrm{NH} 4 \mathrm{Cl}, 1.8 \mathrm{mM}$ $\mathrm{MgCl} 2,5 \%$ glycerol, $0.06 \%$ Igepal CA-630, 0.05\% Tween-20, $0.2 \mathrm{mM}$ dNTPs, $25 \mathrm{U} / \mathrm{ml}$ OneTaq Hot Start DNA Polymerase; New England BioLabs, Inc., Ipswich, MA, USA), $1 \mu 1$ $(0.375 \mu \mathrm{M})$ of each oligonucleotide primer and $7 \mu \mathrm{l}$ of PCR-grade water. The reactions were heated to $94^{\circ} \mathrm{C}$ for $2 \mathrm{~min}$ followed by 35 cycles at $94^{\circ} \mathrm{C}$ for $30 \mathrm{sec}, 60^{\circ} \mathrm{C}$ for $30 \mathrm{sec}$ and $72^{\circ} \mathrm{C}$ for $45 \mathrm{sec}$. Finally, the reactions were extended for $7 \mathrm{~min}$ at $72^{\circ} \mathrm{C}$ using the $\$ 1000$ Thermal Cycler (Bio-Rad, Hercules, CA, USA). PCR products were then separated by electrophoresis on a 3\% agarose gel. For Site 2, after DNA extraction, $200 \mathrm{ng}$ of genomic DNA was subjected to PCR. The PCR primers used for Site 2 assays were: 5'-CAAAATTTTATGA CACTACCAGAATGGCTGAC-3' (forward) and 5'-AACCTT GTACTTCCACATCAGTGCCTGG-3' (reverse). The resulting reaction mixture consisted of $25 \mu \mathrm{l}$ standard PCR buffer, 5\% DMSO, $1.0 \mathrm{mM} \mathrm{MgCl}{ }_{2}, 0.2 \mathrm{mM}$ dNTP, $1 \mathrm{U}$ Taq polymerase (Gibco-Invitrogen, Carlsbad, CA, USA), and $0.4 \mu \mathrm{M}$ of each oligonucleotide primer. PCR cycling conditions were as follows: $3 \mathrm{~min}$ at $94^{\circ} \mathrm{C} ; 35$ cycles of $30 \mathrm{sec}$ at $94^{\circ} \mathrm{C}, 30 \mathrm{sec}$ at $58^{\circ} \mathrm{C}$ and $30 \mathrm{sec}$ at $72^{\circ} \mathrm{C}$; and at $72^{\circ} \mathrm{C}$ for $30 \mathrm{sec}$, PCR products were extended using a Perkin-Elmer GeneAmp System 9700 (Waltham, MA, USA). A $2 \%$ agarose gel stained with ethidium bromide was used to separate and visualize the PCR fragments at $220 \mathrm{~V}$ for $30 \mathrm{~min}$. Both primers provide valid characterization of the PER3 VNTR $(33,42,44-48)$. DNA sequences of amplicons produced by each set of primers were verified via Sanger sequencing. Duplicate genotyping was performed in 
Table I. Demographic characteristics of study population.

\begin{tabular}{|c|c|c|c|c|}
\hline Variable $^{\mathrm{a}}$ & $\begin{array}{l}\text { Total population } \\
\qquad \begin{array}{c}(\mathrm{n}=146) \\
\mathrm{n}(\%)\end{array}\end{array}$ & $\begin{array}{c}\text { Controls } \\
(\mathrm{n}=97) \\
\mathrm{n}(\%)\end{array}$ & $\begin{array}{c}\text { Cases } \\
(\mathrm{n}=49) \\
\mathrm{n}(\%)\end{array}$ & $\begin{array}{l}\text { Cases vs. } \\
\text { controls } \\
\text { P-value }\end{array}$ \\
\hline Sex & & & & 0.32 \\
\hline Male & $105(72)$ & $67(70)$ & $38(78)$ & \\
\hline Female & $40(28)$ & $39(30)$ & $11(22)$ & \\
\hline Race & & & & 0.12 \\
\hline European American & $94(65)$ & $58(60)$ & $36(73)$ & \\
\hline African American & $51(35)$ & $38(40)$ & $13(27)$ & \\
\hline Marital status & & & & 0.46 \\
\hline Unmarried & $38(26)$ & $27(28)$ & $11(22)$ & \\
\hline Married & $107(74)$ & $69(72)$ & $38(78)$ & \\
\hline Education & & & & 0.75 \\
\hline Up to High School & $52(36)$ & $34(35)$ & $18(37)$ & \\
\hline Some College & $40(28)$ & $25(26)$ & $15(31)$ & \\
\hline $\begin{array}{l}\text { College Undergraduate } \\
\text { or Post-Graduate Degree }\end{array}$ & $53(37)$ & $37(39)$ & $16(33)$ & \\
\hline Income level & & & & 0.37 \\
\hline Under $\$ 50,000$ & $63(46)$ & $40(45)$ & $23(49)$ & \\
\hline$\geq \$ 50,000$ to $\$ 100,000$ & $53(39)$ & $38(43)$ & $15(32)$ & \\
\hline$>\$ 100,000$ & $20(15)$ & $11(12)$ & $9(19)$ & \\
\hline Body mass index $\left(\mathrm{kg} / \mathrm{m}^{2}\right)$ & & & & 0.22 \\
\hline Normal $(\leq 25)^{\mathrm{c}}$ & $33(23)$ & $19(20)$ & $14(29)$ & \\
\hline Overweight $(>25)$ & $113(77)$ & $78(80)$ & $35(71)$ & \\
\hline Family history of colorectal cancer & & & & 0.84 \\
\hline Yes & 25 (17) & $17(18)$ & $8(16)$ & \\
\hline No & $120(83)$ & $79(82)$ & $41(84)$ & \\
\hline Diagnosis of diabetes & & & & 0.15 \\
\hline Yes & $42(29)$ & $24(25)$ & $18(38)$ & \\
\hline No & $102(81)$ & $71(75)$ & $31(62)$ & \\
\hline History of smoking & & & & 0.01 \\
\hline Ever & $91(63)$ & $53(56)$ & $38(78)$ & \\
\hline Never & $53(37)$ & $42(44)$ & $11(22)$ & \\
\hline Work decision latitude $^{\mathrm{d}}$ & & & & 0.03 \\
\hline Often or always & $51(35)$ & $28(29)$ & $23(57)$ & \\
\hline Never or sometimes & $21(14)$ & $18(19)$ & $3(6)$ & \\
\hline Unknown & $74(51)$ & $51(53)$ & $23(47)$ & \\
\hline Age group (years) & & & & 0.11 \\
\hline $30-54$ & $45(31)$ & $34(35)$ & $11(22)$ & \\
\hline $55-65$ & $66(46)$ & $44(46)$ & $22(45)$ & \\
\hline$>65$ & $34(23)$ & $18(19)$ & $16(33)$ & \\
\hline Reason for colonoscopy & & & & 0.03 \\
\hline Screening & $78(53)$ & $58(60)$ & $20(41)$ & \\
\hline Surveillance & $68(47)$ & $39(40)$ & $29(59)$ & \\
\hline \multirow{2}{*}{$\begin{array}{l}\text { Lifetime shift } \\
\text { work } \\
\text { (years) }\end{array}$} & \multicolumn{3}{|c|}{ Median (25th, 75 th percentile) } & \\
\hline & $3(0,12.3)$ & $5(0,15)$ & $2(0,10)$ & 0.10 \\
\hline
\end{tabular}

${ }^{\mathrm{a} N u m b e r}$ of subjects for each variable category may not equal total number of subjects due to missing data; ${ }^{\mathrm{b}} \mathrm{Chi}$-squared test for differences in proportions or Wilcoxon rank sum test for differences in medians between cases and controls; ${ }^{c} n=3$ subjects in the underweight BMI category $\left(\leq 18.5 \mathrm{~kg} / \mathrm{m}^{2}\right)$; ${ }^{\mathrm{d}}$ Defined by the question: 'Do you have a good deal of say in decisions about your work?'. 
Table II. PER3 VNTR genotype by adenoma status.

\begin{tabular}{lcccccccc}
\hline Genotype & $\begin{array}{c}\text { Controls } \\
(\mathrm{n}=97) \\
\mathrm{n}(\%)\end{array}$ & $\begin{array}{c}\text { Cases } \\
(\mathrm{n}=49) \\
\mathrm{n}(\%)\end{array}$ & Crude OR & $95 \% \mathrm{CI}$ & P-value & Adjusted OR & $95 \%$ CI & P-value \\
\hline $4 / 4$ & $52(54)$ & $16(33)$ & Ref & - & - & Ref & - & - \\
$4 / 5$ & $38(39)$ & $24(49)$ & 2.1 & $0.9-4.4$ & 0.06 & 2.1 & $0.9-4.8$ & 0.07 \\
$5 / 5$ & $7(7)$ & $9(18)$ & 4.2 & $1.3-13.0$ & 0.01 & 5.1 & $1.4-18.1$ & 0.01 \\
$4 / 5$ or $5 / 5$ & $45(46)$ & $33(67)$ & 2.4 & $1.7-4.9$ & 0.02 & 2.5 & $1.7-5.4$ & 0.02 \\
\hline
\end{tabular}

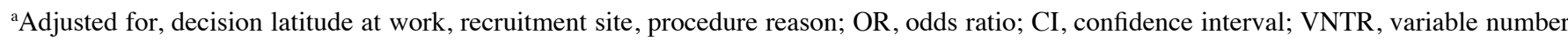
tandem repeat.

$10 \%$ of all samples from both sites for quality control purposes, and there was $100 \%$ concordance among duplicates (42). Hardy-Weinberg equilibrium (HWE) was examined, and gene frequencies for the PER3 VNTR were in HWE among the entire study population $(\mathrm{p}=0.74)$, and among controls from both sites $(\mathrm{p}=0.99)$ or within each site (Site $1, \mathrm{p}=0.94$; Site 2, $\mathrm{p}=0.82$, data not shown).

Statistical analyses were performed using the Statistical Analysis Software $\left(\mathrm{SAS}^{\circledR}\right)$ computer program (version 9.2; SAS Institute, Cary, NC, USA) and the R meta-analysis package (version 2.14.1; http://cran.r-project.org). Potential differences between study variables by case status within the entire study population, and within each site separately, were examined using the Chi-squared test for differences between proportions. Unconditional multiple logistic regression was used to estimate odds ratios (ORs) with $95 \%$ confidence intervals (95\% CIs) for PER3 VNTR genotype among adenoma cases relative to controls using the $4 / 4$ genotype as referent $(33,42)$. Co-variates considered for inclusion in adjusted models were known or suspected adenoma or CRC risk factors [age, gender, race, body mass index (BMI), CRC family history, smoking history, work-related factors, diet, vitamin and supplement use, physical activity, sociodemographic characteristics (income, education), personal medical history], recruitment site and variables that differed among participants and nonparticipants (gender, personal cancer history, ulcer diagnosis, lactose intolerance, secondhand smoke exposure). Final models included variables that were statistically significant $(\mathrm{p} \leq 0.05)$ in the saturated model, or produced at least a $10 \%$ change in the parameter estimate for genotype (decision latitude at work, procedure reason, recruitment site). Differences in median shift work duration by PER3 genotype were compared using the Wilcoxon rank sum test. Ancillary analyses examined relationships between lifetime shift work and adenoma status; or PER3 genotype and adenoma status after stratification by procedure reason (screening vs. surveillance colonoscopy), or shift work (none vs. any, or median split on years of lifetime shift work). Random-effects meta-analysis was used to evaluate the study hypothesis since recruitment occurred at two separate sites. The $\mathrm{I}^{2}$ and $\mathrm{Q}$ statistics were used to assess heterogeneity between sites. Finally, Oncomine (49), a publically accessible gene expression microarray database, was queried to examine potential differential expression of PER1, PER2 and PER3 clock genes in adenomas versus adjacent normal tissue.

\section{Results}

The median age of the participants was 58 years (25-75th percentile: 53-64 years), and they were primarily European American (EA) (65\%), and male (72\%). Most (69\%) participants had engaged in at least one year of shift work (median, 3 years; $25-75$ th percentile: 0-12.3 years). Adenomas were detected in $34 \%$ of participants (females, $28 \%$; males; $36 \%$ ). Compared to controls, cases were more likely to have smoked ( 78 vs. $56 \%$ ), have higher workplace decision latitude (57 vs. $29 \%$ ), and have undergone a surveillance rather than a screening colonoscopy (59 vs. $40 \%$, Table I). The following characteristics were different by site, regardless of case status ( $\mathrm{p} \leq 0.05$, data not shown): gender, race, marital status, income level, ever smoking, age group, reason for procedure and number of years of lifetime shift work. Compared to controls, cases in Site 1 were less likely to be diagnosed with diabetes, more likely to have smoked in the past and more likely to undergo a surveillance colonoscopy (data not shown). Site 2 cases were older compared to controls (data not shown).

Overall PER3 VNTR genotype frequencies (4/4, 47\%; $4 / 5,42 \% ; 5 / 5,11 \%)$ were consistent with those reported previously $(21,33,37-48,50)$. Adenoma cases were more likely than controls to possess one or two copies of the 5-repeat sequence (4/5 OR, 2.1; 95\% CI, 0.9-4.8; 5/5 OR, 5.1; 95\% CI, 1.4-18.1; $4 / 5+5 / 5$ OR, 2.5; 95\% CI, 1.7-5.4, Table II). The distribution of lifetime shift work history varied by PER3 VNTR genotype (Table III). Those with the $4 / 4$ genotype had greater median lifetime years of shift work (5 years) compared to those with the $4 / 5$ ( 2 years, $\mathrm{p}=0.02), 5 / 5(0.75$ years, $\mathrm{p}=0.05)$ or the combined genotype $(4 / 5+5 / 5,1$ year, $\mathrm{p}<0.01)$. Shift work or the combined effect of shift work and genotype was not related to adenoma case status (data not shown). When analyses were stratified by procedure reason, the $5 / 5$ genotype was associated with adenoma status among screening patients (OR, 10.7; 95\% CI, 1.4-80.7), although CIs were wide and no statistically significant relationship was observed among those with other combinations of genotype and procedure reason (data not shown). When the data were evaluated using meta-analytic methods, adenoma cases were $\sim 2-3$ times more likely than controls to have at least one 5-repeat allele, although the CIs were wide and did not achieve statistical significance (4/5 OR, 2.27; 95\% CI, 0.43-11.62; pheterogeneity $_{0} 0.12 ; \mathrm{I}^{2}, 60 \% ; 5 / 5$ OR, 3.02; 95\% CI, 0.72-12.71; $\mathrm{p}_{\text {heterogeneity }}, 0.84 ; \mathrm{I}^{2}, 0 \% ; 4 / 5+5 / 5$ 
Table III. Relationship between PER3 VNTR genotype and lifetime shift work exposure.

$\frac{\text { Lifetime shift work (years) }}{25 \text { th } \quad 75 \text { th }}$

n (\%) Median Percentile Percentile P-value ${ }^{\mathrm{a}}$

\begin{tabular}{lccccc}
\hline $4 / 4$ & $67(47)$ & 5 & 1 & 15 & - \\
$4 / 5$ & $61(42)$ & 2 & 0 & 10 & 0.020 \\
$5 / 5$ & $16(11)$ & 0.75 & 0 & 8.5 & 0.050 \\
$4 / 5$ or $5 / 5$ & $77(53)$ & 1 & 0 & 10 & 0.008
\end{tabular}

${ }^{a}$ Wilcoxon rank sum test for group differences in median duration shift work by genotype using the $4 / 4$ genotype as the referent $(n=2$ subjects with missing data on lifetime shift work). VNTR, variable number tandem repeat.

OR, 2.35; 95\% CI, 0.60-9.21; pheterogeneity $_{\text {, }} 0.14 ; \mathrm{I}^{2}, 54 \%$, data not shown).

Data for PER1, PER2 and PER3 expression in adenomas relative to normal tissue were retrieved from the Oncomine microarray database (Table IV) (51-53). A statistically significant reduction in PER3 expression was observed in adenomas relative to normal tissue among each of the available data sets; similar differences were noted for PERI, and to a lesser extent PER2 expression (Table IV).

\section{Discussion}

Few studies have examined the role of the PER3 VNTR on cancer-related outcomes $(21,33,44,45)$. To our knowledge, this exploratory study is the first to examine the relationship between the PER 3 VNTR and human adenoma risk. Adenoma cases were $\sim 2-5$ times more likely to possess the 5-repeat PER3 length polymorphism compared to controls. Quality criteria for genotyping and colonoscopy were satisfactory $(54,55)$, and adjustment for potential confounding by known or suspected adenoma risk factors did not alter the interpretation of the results. The meta-analysis indicated that the strength of association between PER3 genotype and adenoma status was generally consistent with the main analysis and the results were not strongly impacted by heterogeneity between the sites. Some imprecise risk estimates with wide confidence intervals were observed due to a limited sample size, particularly for the stratified analyses. Thus, examination of possible effect modification by factors such as race, chronotype or procedure indication (screening vs. surveillance) would benefit from a larger sample in future studies. Nonetheless, the lower bound of the confidence intervals suggest an increased risk for adenoma formation of at least $\sim 40 \%$ among homozygous 5-repeat PER3 variants. $P E R$ gene expression was not performed among cases and controls in the present study, thus changes in expression relative to the PER3 VNTR genotype could not be evaluated. However, our query of the Oncomine database indicated that $P E R 3$ and to a lesser extent PER 1 and PER 2 expression was reduced among adenomas compared to normal mucosa, which is consistent with previous studies that observed a reduction in PERI and PER3 expression in human colorectal tumors relative to adjacent normal tissue $(32,36,56,57)$.

The spectrum of known genetic susceptibility markers does not fully account for all CRC cases. For example, 10 loci identified from genome-wide association studies had population attributable risks ranging from 1.7 to $11.9 \%$ (58), and another study reported that up to $35 \%$ of CRC cases are due to heritable factors (59). The present study mirrors previous investigations that have examined clock gene polymorphisms in conjunction with cancer susceptibility $(4,21,33,44,45)$, including one that identified an association between the 5-repeat PER3 VNTR sequence and increased odds of premenopausal breast cancer (33). Evidence suggests that PER3 may function as a tumor suppressor. A recent study among PER3 knockout mice indicated that $36 \%$ of the homozygous null variants developed chemically-induced mammary tumors compared to $12 \%$ among heterozygotes and $0 \%$ among wild-type mice (27). Another recent study used methylation arrays and stringent selection criteria to screen $>14,000$ genes to identify putative tumor suppressors associated with human hepatocellular carcinoma; PER3 was one of only three candidate tumor suppressor genes identified (28). Chronic gastrointestinal inflammation is important for adenoma and CRC development (2), and since PERIOD genes play a role in immune system regulation, their expression may influence these processes $(5,25,26)$. Recently, another PER3 polymorphism (rs2797685) was associated with

Table IV. PERIOD gene expression in human adenomas vs. normal tissue ${ }^{\mathrm{a}}$.

\begin{tabular}{|c|c|c|c|c|c|c|c|c|}
\hline Referent tissue & Pathological tissue type & PERl & P-value & PER2 & P-value & PER3 & P-value & Ref. \\
\hline $\begin{array}{l}\text { Normal colon } \\
\text { epithelium }(n=22)\end{array}$ & $\begin{array}{l}\text { Colorectal adenoma } \\
\text { epithelium }(n=56)\end{array}$ & -1.3 & 0.003 & -1.2 & 0.050 & N/A & N/A & $(51)$ \\
\hline Normal colon $(n=32)$ & Colon adenoma $(n=25)$ & -1.7 & 0.008 & -1.2 & 0.003 & -2.3 & $<0.001$ & $(52)$ \\
\hline Normal colon $(n=32)$ & Rectal adenoma $(n=7)$ & -1.9 & 0.050 & 1.3 & 0.880 & -1.7 & 0.001 & $(52)$ \\
\hline Normal colon $(n=10)$ & Colon adenoma $(n=5)$ & -1.0 & 0.370 & 1.6 & 0.990 & -2.1 & $<0.001$ & $(53)$ \\
\hline $\begin{array}{l}\text { Normal colon } \\
\text { epithelium }(n=10)\end{array}$ & $\begin{array}{l}\text { Colorectal adenoma } \\
\text { epithelium }(n=5)\end{array}$ & -1.2 & 0.050 & 1.2 & 0.940 & -1.7 & 0.005 & $(53)$ \\
\hline
\end{tabular}

${ }^{\text {a}}$ Fold-change in mRNA expression in adenomas relative to adjacent normal tissue (number of tissue samples evaluated in parentheses). Source, www.oncomine.com. 
inflammatory bowel disease, a known CRC risk factor (60). The mechanism whereby PER3 may exert a tumor suppressor function is currently unknown. The clock genes exert genetic and epigenetic regulatory effects that facilitate the circadian expression of $\sim 5-10 \%$ of the entire mammalian transcriptome (6-10), including other known tumor suppressors and oncogenes (e.g., $c-M y c, p 53)(31,61,62)$. Clock genes also help regulate cellular processes that are active during carcinogenesis (cell proliferation, DNA damage response, apoptosis), and clock gene dysregulation may foster adenoma formation by influencing these pathways $(4,11,13,15)$.

Individuals with the 5-repeat PER3 VNTR sequence tend to have relatively penetrant phenotypic characteristics including delayed sleep phase syndrome, increased susceptibility to cognitive impairment after sleep deprivation, morning circadian preference and differences in the timing or levels of circadian hormone secretion $(16,37,40)$, although some inconsistencies have been reported $(21,39,63-65)$. Whether alterations in sleep and other circadian processes can increase cancer susceptibility remains to be determined, although studies of shift work and cancer incidence suggest this is possible $(3,4,24)$. In the present study, participants with the 5-repeat allele reported less cumulative shift work experience relative to those with the $4 / 4$ genotype (Table III). Additional research is needed to determine whether this is a chance finding or if individuals carrying these variants are less tolerant of shift work and self-select out of these occupations relative to those with the $4 / 4$ genotype. Individuals with the 5 -repeat allele may be more susceptible to disturbances in circadian timekeeping $(16,37,40,41)$. For example, those carrying the 5/5 PER3 variant were sensitive to light-induced melatonin suppression whereas $4 / 4$ homozygotes were not responsive (41). Since melatonin has potent antioxidant, antiproliferative and anti-inflammatory properties in the gastrointestinal tract, a reduction in its secretion (e.g., by exposure to light at night) may facilitate physiologic changes that predispose to increased risks for CRC or other cancers $(3,4,20,22,23)$. Although PER3 has tumor suppressor properties and its length polymorphism tends to have relatively penetrant phenotypic characteristics, the role of these factors in cancer susceptibility, if any, remains to be characterized.

In conclusion, the present study indicates that individuals with the 5-repeat PER3 length polymorphism may be more susceptible to adenoma formation. The results are consistent with Oncomine data indicating that PERIOD clock gene expression is reduced in adenomas relative to normal GI tissue. Further interrogation of interrelationships between the PER3 VNTR and genetic or epigenetic pathways that may facilitate adenoma risk, such as changes in the expression of clock-controlled, cancer-related genes, is recommended. Further elucidation of the PER3 VNTR genotype in relation to circadian rhythm or clock gene dysregulation may lead to development of novel, modifiable targets for adenoma and CRC prevention.

\section{Acknowledgements}

The authors declare that there are no conflicts of interest. This study was supported by a supplemental grant from the National Cancer Institute (NCI) as part of the South
Carolina Cancer Disparities Community Network (3 U01 CA114601-03S5, PI, J.R. Hébert; Co-Project Leaders: J.B. Burch and S.E. Steck), and by the parent grant, South Carolina Cancer Disparities Community Network [U01 CA114601 Hebert, J.R. (PI)]. Dr J.B. Burch was supported by a Career Development Award from the USA Department of Veterans Affairs, VISN-7, Charleston, SC, and the Arnold School of Public Health and Center for Colorectal Cancer Research, University of South Carolina, Columbia, SC, USA. Melannie Alexander was supported by the University of South Carolina Behavioral-Biomedical Interface Program, funded in part by training grant T32-5R18CE001240 from the National Institute of General Medical Sciences. Dr J.R. Hébert was supported by an Established Investigator Award in Cancer Prevention and Control from the Cancer Training Branch of NCI (K05 CA136975). Dr S.E. Steck was supported by a University of South Carolina Research Opportunity Award and by the USC Center for Colon Cancer Research (COBRE 5P20RR017698). The South Carolina Medical Endoscopy Center (SCMEC) and the William Jennings Bryant Dorn Veterans Administration Medical Center (DVAMC) served as recruitment sites and provided additional research support. The authors thank Matt Darmer at the Greenwood Genetic Center for providing technical assistance with PCR and Sanger sequencing.

\section{References}

1. Siegel R, Ma J, Zou Z and Jemal A: Cancer statistics, 2014. CA Cancer J Clin 64: 9-29, 2014.

2. Conteduca V, SansonnoD, Russi S and DammaccoF: Precancerous colorectal lesions (Review). Int J Oncol 43: 973-984, 2013.

3. Haus EL and Smolensky MH: Shift work and cancer risk: potential mechanistic roles of circadian disruption, light at night, and sleep deprivation. Sleep Med Rev 17: 273-284, 2013.

4. Lahti T, Merikanto I and Partonen T: Circadian clock disruptions and the risk of cancer. Ann Med 44: 847-853, 2012.

5. Landgraf D, Shostak A and Oster H: Clock genes and sleep. Pflugers Archiv 463: 3-14, 2012.

6. Masri S, Zocchi L, Katada S, Mora E and Sassone-Corsi P: The circadian clock transcriptional complex: metabolic feedback intersects with epigenetic control. Ann NY Acad Sci 1264: 103-109, 2012.

7. Panda S, Antoch MP, Miller BH, et al: Coordinated transcription of key pathways in the mouse by the circadian clock. Cell 109: 307-320, 2002.

8. Schibler U: The daily timing of gene expression and physiology in mammals. Dialogues Clin Neurosci 9: 257-272, 2007.

9. Ripperger JA and Merrow M: Perfect timing: epigenetic regulation of the circadian clock. FEBS Lett 585: 1406-1411, 2011.

10. Storch KF, Lipan O, Leykin I, et al: Extensive and divergent circadian gene expression in liver and heart. Nature 417: 78-83, 2002.

11. Wood P, Yang X and Hrushesky W: The role of circadian rhythm in pathogenesis of colorectal cancer. Curr Colorectal Cancer Rep 6: 74-81, 2010.

12. Kang TH and Sancar A: Circadian regulation of DNA excision repair: implications for chrono-chemotherapy. Cell Cycle 8: 1665-1667, 2009.

13. Yu EA and Weaver DR: Disrupting the circadian clock: genespecific effects on aging, cancer, and other phenotypes. Aging 3 : 479-493, 2011.

14. Yang MY, Yang WC, Lin PM, et al: Altered expression of circadian clock genes in human chronic myeloid leukemia. J Biol Rhythms 26: 136-148, 2011.

15. Chen-Goodspeed M and Lee CC: Tumor suppression and circadian function. J Biol Rhythms 22: 291-298, 2007.

16. Dijk DJ and Archer SN: PERIOD3, circadian phenotypes, and sleep homeostasis. Sleep Med Rev 14: 151-160, 2010.

17. Ebisawa T: Analysis of the molecular pathophysiology of sleep disorders relevant to a disturbed biological clock. Mol Genet Genomics 288: 185-193, 2013. 
18. Thompson CL, Larkin EK, Patel S, Berger NA, Redline S and $\mathrm{Li} \mathrm{L}$ : Short duration of sleep increases risk of colorectal adenoma. Cancer 117: 841-847, 2011.

19. Burch JB, Wirth M and Yang X: Disruption of circadian rhythms and sleep: role in carcinogenesis. In: The Encyclopedia of Sleep. Kushida CA (ed). Vol 3. Academic Press, Waltham, MA, pp150-155, 2013

20. Jiao L, Duan Z, Sangi-Haghpeykar H, Hale L, White DL and El-Serag HB: Sleep duration and incidence of colorectal cancer in postmenopausal women. Br J Cancer 108: 213-221, 2013

21. Wirth MD, Burch JB, Hébert JR, et al: Case-control study of breast cancer in India: Role of PERIOD3 clock gene length polymorphism and chronotype. Cancer Invest 32: 321-329, 2014.

22. Schernhammer ES, Laden F, Speizer FE, et al: Night-shift work and risk of colorectal cancer in the nurses' health study. J Nat Cancer Inst 95: 825-828, 2003.

23. Parent MÉ, El-Zein M, Rousseau MC, Pintos J and Siemiatycki J: Night work and the risk of cancer among men. Am JEpidemiol 176 751-759, 2012.

24. IARC Monographs on the Evaluation of Carcinogenic Risks to Humans. Painting, Firefighting and Shiftwork. International Agency for Research on Cancer. World Health Organization. Vol 98. Lyon, France, 2010.

25. Scheiermann C, Kunisaki Y and Frenette PS: Circadian control of the immune system. Nat Rev Immunol 13: 190-198, 2013.

26. Arjona A, Silver AC, Walker WE and Fikrig E: Immunity's fourth dimension: approaching the circadian-immune connection. Trends Immunol 33: 607-612, 2012.

27. Climent J, Perez-Losada J, Quigley DA, et al: Deletion of the $P E R 3$ gene on chromosome $1 \mathrm{p} 36$ in recurrent ER-positive breas cancer. J Clin Oncol 28: 3770-3778, 2010.

28. Neumann O, Kesselmeier M, Geffers R, et al: Methylome analysis and integrative profiling of human HCCs identify novel protumorigenic factors. Hepatology 56: 1817-1827, 2012.

29. Cao Q, Gery S, Dashti A, et al: A role for the clock gene Perl in prostate cancer. Cancer Res 69: 7619-7625, 2009.

30. Gery S, Komatsu N, Baldjyan L, Yu A, Koo D and Koeffler HP The circadian gene Perl plays an important role in cell growth and DNA damage control in human cancer cells. Mol Cell 22: 375-382, 2006

31. Hua H, Wang Y, Wan C, et al: Circadian gene mPer2 overexpression induces cancer cell apoptosis. Cancer Sci 97: 589-596, 2006.

32. Wang X, Yan D, Teng M, et al: Reduced expression of PER3 is associated with incidence and development of colon cancer. Ann Surg Oncol 19: 3081-3088, 2012.

33. Zhu Y, Brown HN, Zhang Y, Stevens RG and Zheng T: Period3 structural variation: a circadian biomarker associated with breas cancer in young women. Cancer Epidemiol Biomarkers Prev 14: 268-270, 2005

34. Mazzoccoli G, Panza A, Valvano MR, et al: Clock gene expression levels and relationship with clinical and pathological features in colorectal cancer patients. Chronobiol Int 28: 841-851, 2011.

35. Oshima T, Takenoshita S, Akaike M, et al: Expression of circadian genes correlates with liver metastasis and outcomes in colorectal cancer. Oncol Rep 25: 1439-1446, 2011.

36. Mostafaie N, Kállay E, Sauerzapf E, et al: Correlated downregulation of estrogen receptor beta and the circadian clock gene Per1 in human colorectal cancer. Mol Carcinog 48: 642-647, 2009.

37. Wirth M, Burch J, Violanti J, et al: Association of the Period 3 clock gene length polymorphism with salivary cortisol secretion among police officers. Neuro Endocrinol Lett 34: 27-37, 2013.

38. Lázár AS, Slak A, Lo JC, et al: Sleep, diurnal preference, health, and psychological well-being: a prospective single-allelicvariation study. Chronobiol Int 29: 131-146, 2012.

39. Pereira DS, Tufik S, Louzada FM, et al: Association of the length polymorphism in the human Per3 gene with the delayed sleep-phase syndrome: does latitude have an influence upon it? Sleep 28: 29-32, 2005.

40. Viola AU, Chellappa SL, Archer SN, et al: Interindividual differences in circadian rhythmicity and sleep homeostasis in older people: effect of a PER3 polymorphism. Neurobiol Aging 33: 1010.e17-1010.e27, 2012.

41. Chellappa SL, Viola AU, Schmidt C, et al: Human melatonin and alerting response to blue-enriched light depend on a polymorphism in the clock gene PER3. J Clin Endocrinol Metab 97: E433-E437, 2012.

42. Guess J, Burch JB, Ogoussan K, et al: Circadian disruption, Per3, and human cytokine secretion. Integr Cancer Ther 8: 329-336, 2009.

43. Benedetti F, Dallaspezia S, Colombo C, Pirovano A, Marino E and Smeraldi E: A length polymorphism in the circadian clock gene Per3 influences age at onset of bipolar disorder. Neurosci Lett 445: 184-187, 2008.
44. Dai $\mathrm{H}$, Zhang L, Cao M, et al: The role of polymorphisms in circadian pathway genes in breast tumorigenesis. Breast Cancer Res Treat 127: 531-540, 2011

45. Karantanos T, Theodoropoulos G, Gazouli M, et al: Association of the clock genes polymorphisms with colorectal cancer susceptibility. J Surg Oncol 108: 563-567, 2013.

46. Ebisawa T, Uchiyama M, Kajimura N, et al: Association of structural polymorphisms in the human period 3 gene with delayed sleep phase syndrome. EMBO Rep 2: 342-346, 2001

47. Nievergelt CM, Kripke DF, Barrett TB, et al: Suggestive evidence for association of the circadian genes PERIOD3 and ARNTL with bipolar disorder. Am J Med Genet B Neuropsychiatr Genet 141B: 234-241, 2006.

48. Archer SN, Robilliard DL, Skene DJ, et al: A length polymorphism in the circadian clock gene Per 3 is linked to delayed sleep phase syndrome and extreme diurnal preference. Sleep 26: 413-415, 2003.

49. Rhodes DR, Kalyana-Sundaram S, Mahavisno V, et al: Oncomine 3.0: genes, pathways, and networks in a collection of 18,000 cancer gene expression profiles. Neoplasia 9: 166-180, 2007.

50. Barbosa AA, Pedrazzolli M, Koike BD and Tufik S: Do Caucasian and Asian Clocks Tick Differently? Braz J Med Biol Res 43: 96-99, 2010.

51. Gaspar C, Cardoso J, Franken P, et al: Cross-species comparison of human and mouse intestinal polyps reveals conserved mechanisms in adenomatous polyposis coli $(A P C)$-driven tumorigenesis. Am J Pathol 172: 1363-1380, 2008.

52. Sabates-Bellver J, Van der Flier LG, de Palo M, et al: Transcriptome profile of human colorectal adenomas. Mol Cancer Res 5: 1263-1275, 2007.

53. Skrzypczak M, Goryca K, Rubel T, et al: Modeling oncogenic signaling in colon tumors by multidirectional analyses of microarray data directed for maximization of analytical reliability. PLoS One 5: pii: e13091, 2010.

54. Xirasagar S, Hurley TG, Sros L and Hebert JR: Quality and safety of screening colonoscopies performed by primary care physicians with standby specialist support. Med Care 48: 703-709, 2010

55. Rex DK, Kahi CJ, Levin B, et al: Guidelines for colonoscopy surveillance after cancer resection: a consensus update by the American Cancer Society and US Multi-Society Task Force on Colorectal Cancer. CA Cancer J Clin 56: 160-167; quiz 185-166, 2006.

56. Krugluger W, Brandstaetter A, Kállay E, et al: Regulation of genes of the circadian clock in human colon cancer: reduced period- 1 and dihydropyrimidine dehydrogenase transcription correlates in high-grade tumors. Cancer Res 67: 7917-7922, 2007.

57. Karantanos T, Theodoropoulos G, Gazouli M, Vaiopoulou A, Karantanou C, Lymberi M and Pektasides D: Expression of clock genes in patients with colorectal cancer. Int J Biol Markers 28: 280-285, 2013

58. Tenesa A and Dunlop MG: New insights into the aetiology of colorectal cancer from genome-wide association studies. Nat Rev Genet 10: 353-358, 2009.

59. Tomlinson IP, Dunlop M, Campbell H, et al: COGENT (COlorectal cancer GENeTics): an international consortium to study the role of polymorphic variation on the risk of colorectal cancer. Br J Cancer 102: 447-454, 2010.

60. Mazzoccoli G, Palmieri O, Corritore G, et al: Association study of a polymorphism in clock gene PERIOD3 and risk of inflammatory bowel disease. Chronobiol Int 29: 994-1003, 2012.

61. Lee CC: The circadian clock and tumor suppression by mammalian period genes. Methods Enzymol 393: 852-861, 2005

62. Gery S and Koeffler HP: Circadian rhythms and cancer. Cell Cycle 9: 1097-1103, 2010.

63. Voinescu BI and Coogan AN: A variable-number tandem repea polymorphism in PER3 is not associated with chronotype in a population with self-reported sleep problems. Sleep and Biological Rhythms 10: 23-26, 2012.

64. Osland TM, Bjorvatn BR, Steen VM and Pallesen S: Association study of a variable-number tandem repeat polymorphism in the clock gene PERIOD3 and chronotype in Norwegian university students. Chronobiol Int 28: 764-770, 2011.

65. Barclay NL, Eley TC, Mill J, et al: Sleep quality and diurnal preference in a sample of young adults: associations with $5 H T T L P R$, PER3, and CLOCK 3111. Am J Med Genet B Neuropsychiatr Genet 156B: 681-690, 2011. 